\title{
Investigation of Infiltration Rate onSoft Claythat Affecting the Ponding Time
}

\author{
Mohd Shalahuddin Adnan ${ }^{1, *}$, Mohd Aliff Mohd Anuar ${ }^{2}$, Muhammad $\mathrm{Nda}^{2}$ and Siti \\ Nazahiyah Rahmat ${ }^{1}$ \\ ${ }^{1}$ Micropollutant Research Centre, Department of Water and Environment Engineering, Universiti \\ Tun Hussein Onn Malaysia (UTHM), 86400 Parit Raja, Johor, Malaysia \\ ${ }^{2}$ Department of Water and Environment Engineering, Universiti Tun Hussein Onn Malaysia \\ (UTHM), 86400 Parit Raja, Johor, Malaysia
}

\begin{abstract}
Malaysia is a country that has abundant rainfall that depends on the seasonal such as monsoon, where,certain areas in peninsular area are expected to receive heavy rain during this monsoon season. This abundant of rain could lead to massive flood if no mitigation actions were taken. One of the factor that contribute to the flood occurrences is type of soils. Type of soils play an important role in determining the rate of infiltration. Thus, this study was conducted to investigate the infiltration rate that effecting the ponding time at the Universiti Tun Hussein Onn Malaysia (UTHM). This area is located at flat topography with thick layer of clay soil beneath the ground surface that indicated low infiltration capacity rate. This condition could causeponding of water that could lead to high surface runoff that could cause flood.This paper was aimed at understanding the effect of soil clay layer on infiltration rate and ponding time. Infiltration test was conducted at four (4) points to make a spatial analysis around the study area. The soil was classified based on soil classification system (USCS), while, ponding time was calculated based on Horton model. Based on the results, the average infiltration rate is ranging from 0.004 $\mathrm{mm} / \mathrm{s}$ to $0.076 \mathrm{~mm} / \mathrm{s}$ among the selected locations. Soil samples were sieve and thedominant soil comprises of minimal well graded silty clay and clayey sand which is more than $50 \%$ content sand and more than $12 \%$ content fines. Lastly, time of ponding was calculated by using Horton model and it shows that the ponding time started between $0.51 \mathrm{~h}$ to $1.0 \mathrm{~h}$. This information could serve a vital information on determining the mitigation measures to tackle a flood problem in this area.
\end{abstract}

\section{Introduction}

Infiltration is one of the important processes in hydrologic cycle where this process can be translate into a process that water seeps into the ground through soil originate from water on the surface. The infiltration capacity primarily determine by the surface cover and properties of underlying soil. Infiltration capacity is much influenced by the underlying

*Corresponding author: shalahudin@uthm.edu.my 
soil, where, a compacted soil like clay has a low infiltration rate compared to loose soil like sand. Normally clay soil has solid connection between the particles that reduce the pore size that contribute to the less space between the pore. This condition has led to decrease in infiltration rate. A study by Selim[1], discovered that the increasing of clay percentage has led to decreasing in soil infiltration. Infiltration is influenced by the hydraulic properties of soil, rainfall intensity and water content distribution with depth [2].

Undeveloped land has very little surface runoff, where, most of the rainfall soaks into the top soil and travel slowly through the soil mantle, as interflow to the stream, lakes or estuary.However, as the watershed developed and the land is covered over with an impervious surface (e.g. roads, parking lots, roofs, driveways and sidewalks) most of the rainfall is transformed into surface runoff. This will result in tremendous increasing in surface runoff and create the unbalance situation in hydrological cycle. Normally, it will resulted in the changes of proportion of evapotranspiration, runoff and infiltration [3].Accurate description of infiltration and post-ponding runoff remains a fundamental problem in hydrology. Water added to an unsaturated soil will be absorbed until it ponds on the surface.

There are several studies have been conducted related with infiltration and ponding time. Based on their study, there are several factors that affecting the infiltration rate such as soil texture and structure, conditions at soil surface, soil moisture content, type of vegetative covers, soil temperature, human activities on soil surface, soil density and biological crusts [4]. Owing to that, many researchers have contributed to the extensive study on the determining of infiltration rate as well as the ponding time in exploring the relationship among these factors. The prediction of ponding time is crucial as the time condensation approximation (TCA) remains a widespread practical tool. TCA basically assumes that at ponding there is a unique relationship between the cumulative infiltration and the flux, independent of previous history.In order to estimate the portion of precipitation that enters the soil and that which becomes overland flow, calculations require estimates of ponding time $[5,2]$.

The understanding of soil properties as well the soil strata is very important before any development being implemented. In addition, this information will be used as a design criteria. Even though, many studies were conducted in determined the infiltration rate and capacity, but, low number of study was conducted to determine the ponding time. The ponding time could provide an information such as time taken for water to start Thus, In Malaysia, the conventional drainage systems that constructed using concrete arewidely used. This practice brings a significant impact on the environment as a whole where, concrete drains tend to cause flooding as runoff is being conveyed to watercourses directly in shorter duration and have less infiltration into the ground. Besides, the conventional drainage systems are highly exposed to clogging problems. As a result, water cannot flow properly to the catchment area. When heavy rain occurs, it can result in high water volume and spills out of the drains and then cause flooding[6].Thus, in this study the effect of soil types on infiltration rate as well as the determination of ponding time was conducted which could be used as guidance for the emergency response.

\section{Methodologies}

\subsection{Study area}

This study was conducted at Universiti Tun Onn Malaysia (UTHM) campus which is located in western part of Malaysia with coordinates $1.8529^{\circ} \mathrm{N}, 103.0866^{\circ} \mathrm{E}$ within Parit Raja, Batu Pahat, Johor (Fig. 1). The average rainfall distribution in this area is ranging 
between $2250-2600 \mathrm{~mm} /$ year [6]. Since the expansion of this campus, the coverage of impermeable layer was increased compared to last 10 years. The development area consists of schools blocks, administration blocks, hostels and also infrastructures component such as roads, covered sidewalk, open sidewalk and many more.

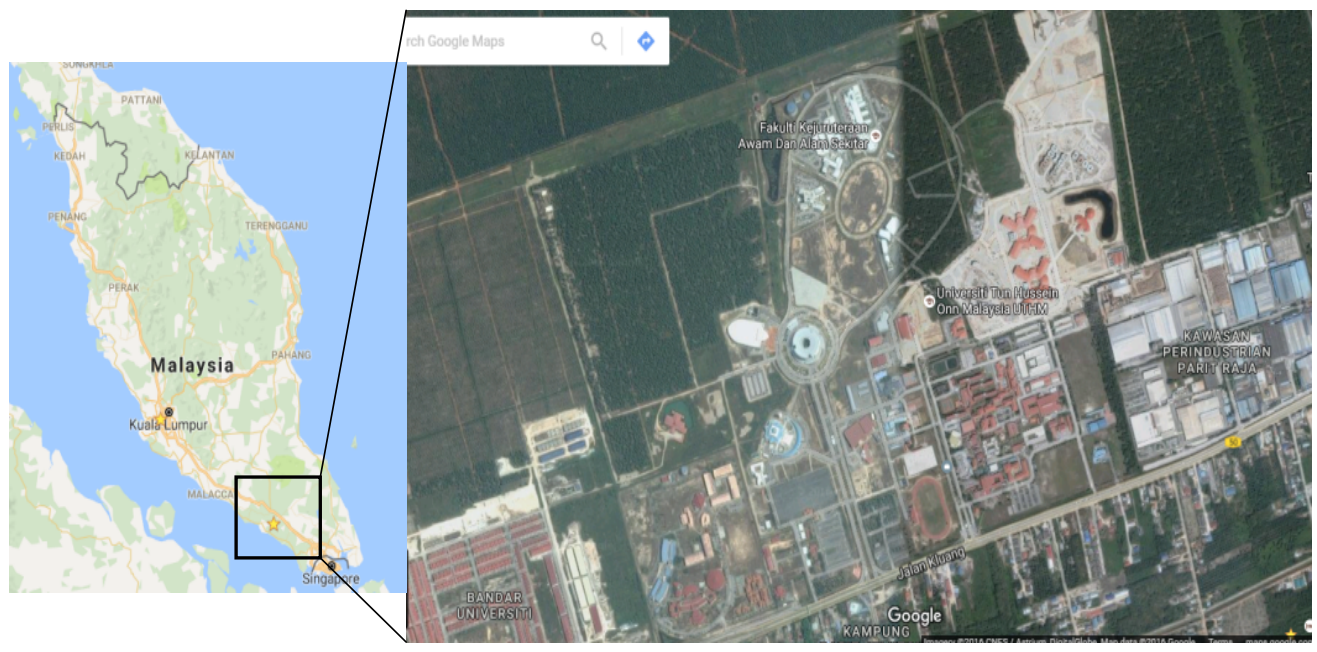

Fig. 1. Location of study area located at Universiti Tun Hussein Onn Malaysia.

\subsection{Sampling Method}

Data collection is an essential part in completing this study. In this study, data collection was separated into two (2) which are primary and secondary data collection. For primary data collection, the infiltration rate, soil sampling, sieve analysis and rainfall were collected at the site by using appropriate apparatus and methods. On the other hand, for secondary data such as historical rainfall data, borelog report, infiltration test results, land use information, and topography were retrieved from respected local authority, library and journals [7].

Before the experimental was conducted, informationof the study areawas obtained to determine the suitable methods that will be applied. Based on preliminary study, sampling points were determined, while, the hydrological data such as precipitation data was derived from Department of Irrigation and Drainage (DID), topography dataand land use data of the study area were collected from University Facilities Centre.

\subsubsection{Soil sampling and Infiltration test}

Further exploration of the subsoil condition within the study area was made to provide additional data for further analysis. This includes soil sampling and infiltration tests where six locations were randomly selected. Moreover, previous borelog data was referred as reference to establish the soil profile by combing with the latest soil sampling.

For infiltration test, double ring infiltrometer instrument was used to determine the infiltration rate. The rate of infiltration is determined as the amount of water per surface area and time unit that penetrates the soil. This rate can be calculated on the basis of the measuring results and the Law of Darcy. The measurements exclusively take place in the inner ring through which the water runs virtually vertically.From the data collection, some 
early indication of soil type of the area can be determined.On the other hand, soil samples collected from borehole was brought back to laboratory to undergone sieve analysis and plasticity index tests.

\subsubsection{Laboratory test}

All of the soil samples taken from the field test were taken to the laboratory for further soil analysis. The Particle Size Distribution for fine and course-grained soil test was carried out in accordance with the procedures in BS 1377. The soil description is based on unified soil classification system (USCS).

\subsubsection{Determination of ponding time}

Infiltration, time to ponding, and runoff generation areconsidered as they manifest in three soils simulated to havebeen exposed to a natural rainfall event with highly variableintensity. The specific focus here is put on ponding time considering (1) the effect of the time interval for averagingrainfall intensity data and (2) the effect of the soil surfacesealing.The rainfall intensitywas used to calculate the ponding time using Horton Model Method. Equation 1 and 2 were utilized for the purpose of ponding time calculation.

Based on Horton Model, the calculation of ponding time can be divided into two (2) conditions as follows;

Continuous water ponding

$$
f_{(t)}=f_{c} t+\frac{f_{o}-f_{c}}{k}\left(1-e^{-k t}\right)
$$

Non continuous water ponding

$$
f=\left[\frac{f_{c}}{k} \ln \left(f_{o}-f_{c}\right)+\frac{f_{o}}{k}\right]-\frac{f_{c}}{k}
$$

Where;

$$
\begin{aligned}
& \mathrm{f}_{\mathrm{o}}=\text { initial infiltration rate } \\
& \mathrm{f}_{\mathrm{c}}=\text { asymtptotic infiltration rate } \\
& \mathrm{k}=\text { decay constant } \\
& \mathrm{f}=\text { potential infiltration rate } \\
& \mathrm{t}=\text { time }
\end{aligned}
$$

\section{Results and Discussion}

\subsection{Soil type and Infiltration rate}

In order to determine the soil strata underneath the land surface, soil sampling were conducted at the same site where infiltration rate was conducted. On the other hand, comparison with available borelog was made. Based on the sieve analyses, the dominant soil type which less than 10 meters depth consist of mainly well graded silty, clay, and clayey sand. This result showed a good agreement with the borelog data.

Based on the infiltration test, the infiltration rate and infiltration capacity were constructed as shown in Fig 2. The range of infiltration rate obtained for this study area ranges between $0.0044 \mathrm{~mm} / \mathrm{s}$ to $0.1167 \mathrm{~mm} / \mathrm{s}$ (Table 1). Based on this table, the value of 
infiltration for each station in varies due to different properties of each location. Station 1 shows the highest values of infiltration while the lowest value was recorded at Station 2. By referring to soil sampling and the available borelog data, the soil at station 2 and Station 6 consist of compacted soil which has less pore compared to non-compacted soil. A study byGregory et al.[8] has express that the value of runoff was increased not only due to the increase in impervious area associated with development but also due to compacted soil.

Table 1. Infiltration rate $(\mathrm{mm} / \mathrm{s})$ for each station

\begin{tabular}{|c|c|c|c|c|c|c|}
\hline & Station 1 & Station 2 & Station 3 & Station 4 & Station 5 & Station 6 \\
\hline Maximum & 0.1167 & 0.0056 & 0.0167 & 0.0167 & 0.0167 & 0.0083 \\
\hline Minimum & 0.0515 & 0.0044 & 0.0083 & 0.0093 & 0.0071 & 0.0051 \\
\hline Average & 0.0795 & 0.0050 & 0.0098 & 0.0129 & 0.0085 & 0.0057 \\
\hline
\end{tabular}

Fig.2(a) shows the graph of infiltration rate against time for station 1. Based on this graph, it clearly shows that infiltration rate was slowly decreased within time. The line stated that the water was slowly decreased infiltrated into the soil based on time. The range of infiltration rate at this station is from $0.0515 \mathrm{~mm} / \mathrm{s}$ to $0.1167 \mathrm{~mm} / \mathrm{s}$.Moreover, the infiltration capacity was calculated as well to determine the maximum rate at which water can be absorbed by a soil. For station 1, high infiltration capacity was observed which show a sharp increment from the beginning of measurement until it become consistent and stagnant at value of $72 \mathrm{~mm}$ which take about 0.42 hours. Even though, the dominant soil in this area is clay, but, the land cover, soil protection and human activities contributes to the infiltration rate. High infiltrationrates were a consequence of improved soil properties, which can provide a high protectionfor soils against degradation or erosion. Therefore, the infiltration rate can reflect the level ofsoil protection[9].

Fig.2(b) shows the graph of infiltration rate against time for station 2. Based on this graph, it clearly shows that the infiltration rate is very low and took a longer time to infiltrate into the soil. This condition is due to the soil condition as this site where the top soil consist of compacted soil that lead to less void space between the soil particle. Even the experiment time was extended for a longer duration, the infiltration rate is still low. While, the infiltration capacity also revealed the same results where the values of infiltration capacity is low in the range of $15-18 \mathrm{~mm}$ at $0.694 \mathrm{hr}$.This shows that the infiltration capacity is significantly affected by the soil types as well as the behavior of the top soil. A study by Dejun et al. [10] has concluded that the sequence of soil infiltration capacity is coarse $>$ fine $>$ very fine $>$ medium $>$ medium fine, consistent to the sequence of soil saturated hydraulicconductivity Ks. The value of infiltration capacity is significantly affected by the pore size and void ratio of the soil particles.

On the other hand, the soil condition also plays an important role that affecting the value of infiltration rate and infiltration capacity. If the experimental was conducted after the rainfall event, the value of infiltration rate will be significantly low due to low infiltration capacity. During this time, the soil condition in saturated condition where the water still there and this greatly affected the infiltration rate. The infiltration rate is affected by the sediment (soil) texture and structure, the condition of the sediment surface, the distribution of soil moisture or soil moisture tension, the chemical and physical nature of the water, the head of the applied water, the depth to ground water, the length of time of application of water, biological activity, the temperature of the water and the type of equipment or method used [11]. 

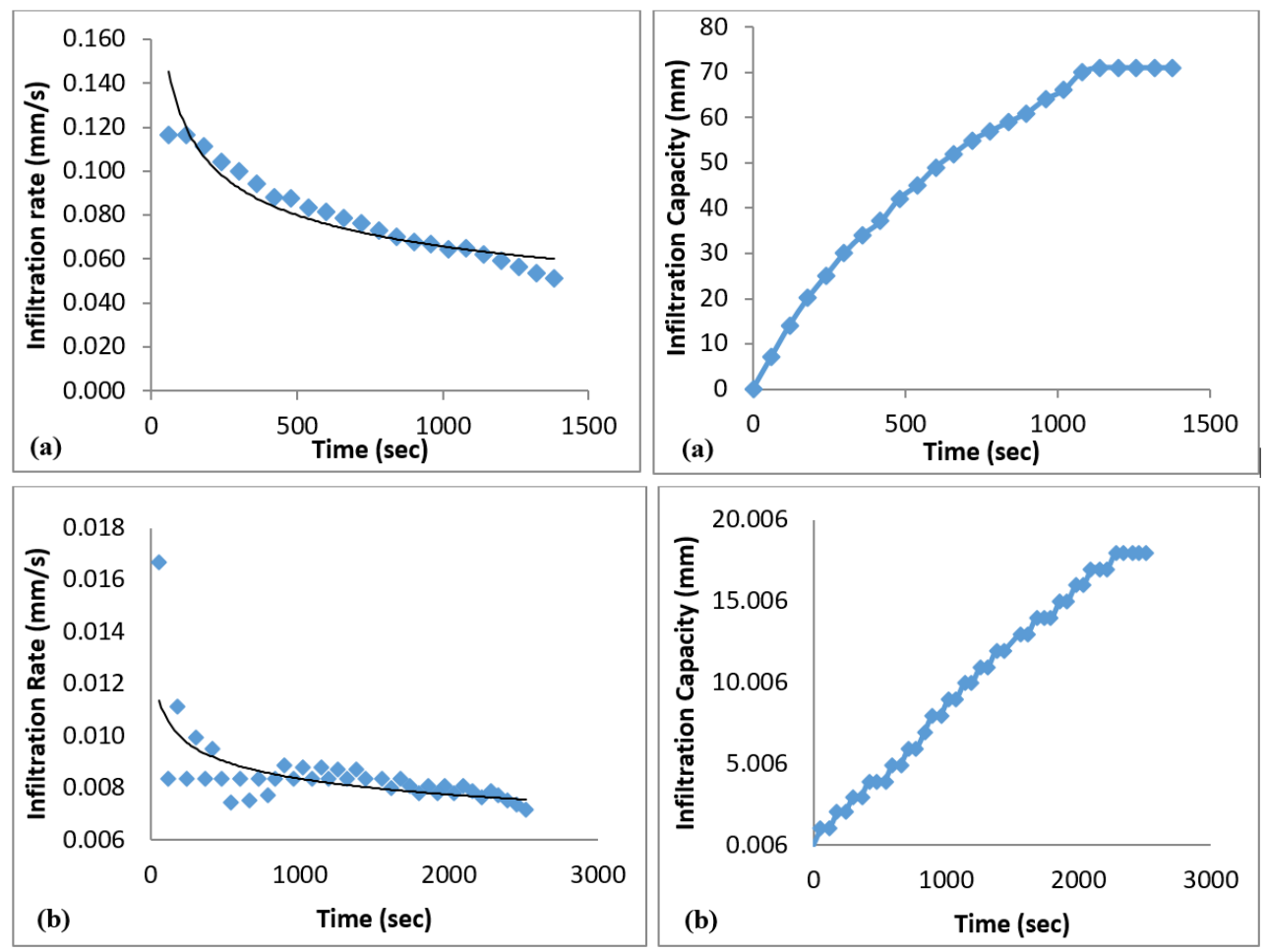

Fig. 2. Infiltration rate and capacity curves for (a) station 1 and (b)station 2

\subsection{Ponding time}

The ponding time corresponding with the infiltration rate, the increasing or decreasing of infiltration rate will significantly influenced the ponding time. Based on all six sampling stations, the ponding time is shows a good agreement with the infiltration rate results. Out of six stations, only Station 1 shows no ponding occurred with the same rainfall intensity used (Table 2). The ponding occurrences could be estimated when the value of runoff is increasing. The increasing of runoff values show that the soil is fully saturated and no infiltration occurred.

For Station 1, there is no ponding was observed since the value of runoff is zero. However, this result can be further improved by extending the time as well as the changes of rainfall intensity. The differences in rainfall intensity could produce different results since the pattern of runoff will be difference. The runoff value is ranging between $9.82 \mathrm{~mm}$ to $57.6 \mathrm{~mm}$.

Based on the calculated results, water ponding was observed to occur during precipitation and the beginning time recorded is $0.30 \mathrm{hr}$. This value is corresponding with the soil type and rainfall intensity. The averaging time interval of rainfall relatively produced accurate estimation of time to peak that influenced the ponding time. The short duration of time to peak could tell us that value of runoff tend be increased [2]. In their study, they also mentioned about the soil type that play an important role in determining the ponding time. 
Table 2.Summary of ponding occurrences

\begin{tabular}{|c|c|c|c|c|c|c|c|}
\hline $\begin{array}{c}\text { Time } \\
(\mathbf{m i n})\end{array}$ & $\begin{array}{c}\text { Station } \\
\mathbf{1}\end{array}$ & $\begin{array}{c}\text { Station } \\
\mathbf{2}\end{array}$ & $\begin{array}{c}\text { Station } \\
\mathbf{3}\end{array}$ & $\begin{array}{c}\text { Station } \\
\mathbf{4}\end{array}$ & $\begin{array}{c}\text { Station } \\
\mathbf{5}\end{array}$ & $\begin{array}{c}\text { Station } \\
\mathbf{6}\end{array}$ & condition \\
\hline 0 & - & - & - & - & - & - & - \\
\hline 10 & Not & Not & Not & Not & Not & Not & $\mathrm{i}<\mathrm{fp}$ \\
\hline 20 & Not & Occur & Not & Not & Not & Not & $\mathrm{i}<\mathrm{fp}$ \\
\hline 30 & Not & Occur & Occur & Occur & Occur & Occur & $\mathrm{i}<\mathrm{fp}$ \\
\hline 40 & Not & Occur & Occur & Occur & Occur & Occur & $\mathrm{i}<\mathrm{fp}$ \\
\hline 50 & Not & Occur & Occur & Occur & Occur & Occur & $\mathrm{i}<\mathrm{fp}$ \\
\hline 60 & Not & Occur & Occur & Occur & Occur & Occur & $\mathrm{i}<\mathrm{fp}$ \\
\hline
\end{tabular}

\section{Conclusion}

UTHM surrounded with pavement area and located at the low lying area with low infiltration capacity which makes this are prone to flood problem. In this study, the determination of soil is so important which could provide an important information on the soil types as well as the soil properties. Based on sieve analysis, it clearly shows that the dominant soil types in this study area comprises a minimal of well graded silty clay or clayey sand with the infiltration rate ranging in between $0.004 \mathrm{~mm} / \mathrm{s}$ to $0.076 \mathrm{~mm} / \mathrm{s}$. Moreover, based on Horton model, the beginnings of ponding time start ranging from $0.30 \mathrm{hr}$ to $1.0 \mathrm{hr}$ while the total runoffs are ranging in from $9.82 \mathrm{~mm}$ to $57.6 \mathrm{~mm}$. On the other hand, suggestion to overcome the problem can be suggested to improve a drainage and retention basin to avoid critical water ponding during heavy rain.

This paper was funded by Universiti Tun Hussein Onn Malaysia (UTHM), Malaysia, The Ministry of Higher Education Malaysia.

\section{References}

[1] T. Selim, The effect of land use on soil infiltration rate in a heavy clay soil in Egypt, Vatten, 67(1998), 161-166, (2011)

[2] S. Assouline, J. S. Selker and J. Y. Parlange, A simple accurate method to predict time of ponding under variable intensity rainfall, Water Resour. Res., 43(3), 1-10, (2007)

[3] M. F. Yusof, N. A. Zakaria, A. A. Ghani, R. Abdullah and C. C. Kiat, Infiltration Study for Urban Soil: Case Studies - Butterworth and Engineering Campus, Universiti Sains Malaysia,Proc. Congr. Assoc. Hydraul. Res., 1, 1154-1162, (2005)

[4] O. S. Mangala, P. Toppo and S. Ghoshal, Study of Infiltration Capacity of Different Soils,Int. J. of Trend in Research and Development, 3(2),388-390, (2016)

[5] M.C. Donoso and N.M. VargasHim-Gonzalez, Water Interactions with Energy, Environment, Food and Agriculture: Water Resources for Agriculture and Food Production, I. (2009)

[6] M.S. Adnan, E. Yuliarahmadila, C.A. Norfathiah and H. Kasmin, Flood simulation using rainfall-runoff for Segamat River Basin,Proc. of the Int. Conf. on Civil, Architectural, Structural and Constructional Eng., Dong-A University, Busan, South Korea, 369-373, (2016)

[7] S. Musa, N.A. Zakaria, D. Tjahjanto and L. Sai, The Potential of Recharge Well System in Flat Area with Low Infiltration Rate,International Conference on Water 
Resources (ICWR 2009), 1-4, (2009)

[8] J. Gregory, M. Dukes, P. Jones and G. Miller, Effect of urban soil compaction on infiltration rate, J. Soil Water Conserv., 61(3), 117-124, (2006)

[9] R. Alhassoun, Studies on factors affecting the infiltration capacity of agricultural soils, $\mathrm{PhD}$ thesis, Universität Carolo-Wilhelmina,(2009)

[10]Y. Dejun, B. Zhengfu, L. Shaogang, M. Shouguo and X. Jibing, Study on Modelling Infiltration Responses of Typical Top Soils Based on Infiltration Models,J. Residuals Sci. Technol., 12(1), 123-131, (2015)

[11]A.I. Johnson, A Field Method for Measurement of Infiltration,Geol. Surv. WaterSupply Paper 1544-F, USGS, US, 27, (1991) 